\title{
A SIMULATION OF THE EFFECT OF GPS PSEUDOLITE OBSERVATIONS ON THE OBSTRUCTED SKY VIEW
}

\author{
Fang-Shii Ning ${ }^{1}$, Szu-Pyng Kao ${ }^{1}$, Chia-Chyang Chang ${ }^{2}$, and Xiaolin Meng ${ }^{3}$ \\ ${ }^{1}$ Department of Civil Engineering, National Chung-Hsing University, Taichung City, \\ Taiwan \\ ${ }^{2}$ Department of Information Management, Yu-Da College of Business, Miaoli, Taiwan \\ ${ }^{3}$ Institute of Engineering Surveying and Space Geodesy, University of Nottingham, \\ United Kingdom
}

\begin{abstract}
GPS has been used in positioning and navigation for decades. However, there are still many unsolved problems existing, for instance the degradation of positioning precision when the view of sky is obstructed. Pseudolite, a ground-based GPS satellite-like signal transmitter, can provide extra measurements in order to improve the positioning precision from GPS alone in the obstructed areas. In this study, pseudolite data were collected to tackle the obstruction of GPS satellite signals, and to evaluate the effectiveness of the GPS pseudolite. The results of this study demonstrated that the pseudolite observations reduced the effect of dilution of precision (DOP) by more than $35 \%$ and positioning precision by $40 \%$, and with the addition of extra measurements it made $1 \mathrm{~cm}$ positioning possible even in the obstructed areas.
\end{abstract}

\section{INTRODUCTION}

Global navigation satellite system (GNSS) such as GPS is playing an increasing role in geodesy, navigation and other applications. It is well known that the positioning accuracy, availability and reliability of GNSS are largely affected by both the number and geometric distribution of the satellites being tracked [2]. Under certain observation conditions, such as in urban canyons and mountainous valleys or under dense foliage, there may not be enough visible GPS satellites. In addition, the satellites tracked may not be well distributed due to the geographical locations and the signal obstruction, and thereby produce a poor satellite geometry. In GPS positioning, the horizontal coordinates are basically more accurate than the vertical component since low elevation satellites are not tracked to avoid signal degradation caused by the atmosphere [6]. This greatly limits the application of GPS in the areas where uniform 3D positioning accuracy is required. One typical example is GPS-based structural 
deformation monitoring where the vertical coordinate is used to detect the potential damage of the structure for safety reason [3]. All the problems can however be resolved by combining additional ranging signals transmitted from ground-based “pseudo-satellite” (pseudolite or PL), with actual GPS measurements [1][5][8].

Pseudolites can be set up on the ground to increase the number of GPS signal transmitters and to improve their spatial distribution, and thereby increase the positioning precision [4]. This study has been designed to use actual GPS+PL observables to simulate obstructed situations by excluding the observations of certain satellite from the data files. The dilution of precision (DOP) value and positioning precision are then estimated for GPS data alone and GPS+PL combined data to quantify the effectiveness of proposed approach and the precision improvement in 3D positioning.

\section{PSEUDOLITE OBSERVATION EQUATIONS}

The GPS observables are defined as the pseudo-range and carrier phase, which can also apply to pseudolite observables as [9]:

$$
\begin{aligned}
& R_{K}^{P}=\rho_{K}^{P}+c \cdot\left(d t^{P}-d t_{k}\right)+T_{K}^{P}+d r_{K}^{P}+d m_{K}^{P}+\varepsilon_{K}^{P} \ldots \ldots \ldots \ldots . . . . . \\
& \phi_{K}^{P}=\frac{1}{\lambda_{P}} \rho_{K}^{P}+\frac{c}{\lambda_{P}} \cdot\left(d t^{P}-d t_{k}\right)+N_{K}^{P}+\frac{1}{\lambda_{P}} T_{K}^{P}+\frac{1}{\lambda_{P}} d r_{K}^{P}+\delta m_{K}^{P}+e_{K}^{P}
\end{aligned}
$$

Where

$R_{K}^{P}$ is the measured pseudo-range between receiver $K$ and pseudolite $P$;

$\phi_{K}^{P}$ is the measured carrier phase in cycles from pseudolite $P$ to receiver $K$;

$\lambda_{P}$ is the signal wavelength of the pseudolite signal;

$\rho_{K}^{P}$ is the geometric distance between site $K$ and pseudolite $P$;

c is the velocity of light;

$d t^{P}$ is the clock error of pseudolite;

$d t_{k}$ is the clock error of the receiver;

$N_{K}^{P}$ is the integer ambiguity;

$T_{K}^{P}$ is the tropospheric delay;

$d r_{K}^{P}$ is the location error of pseudolite;

$d m_{K}^{P}$ and $\delta m_{K}^{P}$ are the multipath signatures on the pseudo-range and the carrier phase, respectively;

$\varepsilon_{K}^{P}$ and $e_{K}^{P}$ are the measured errors of the pseudo-range and carrier phase, 
respectively.

Pseudolites do not have a high quality clock (unlike the GPS satellites), therefore double difference of the carrier phase is generally applied to eliminate the clock bias from the pseudolite observables. For example, as shown in Figure 1, there is no external time oscillator equipment in the pseudolite, hence the clock bias of pseudolite transmitter cannot be calibrated before data collection. In data processing, double difference of carrier phase measurements is the way to obtain precise baseline solutions.

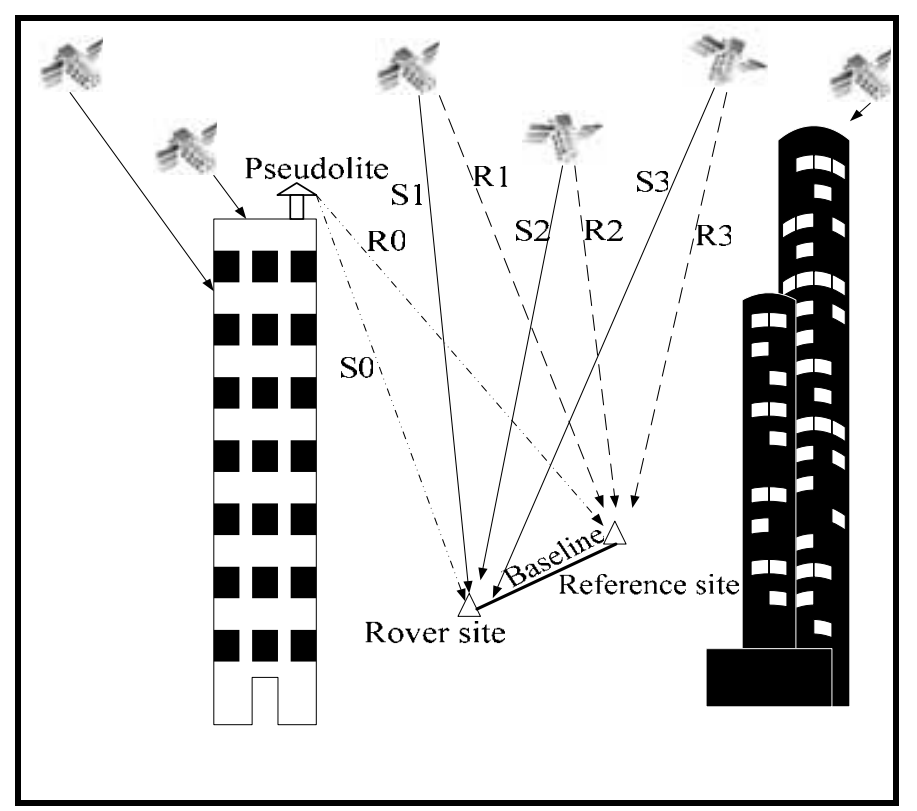

Fig.1. Double difference for processing GPS and PL observations

\section{SIMULATION OF OBSTRUCTIONS}

\section{Raw Data Collection}

For the simulation of obstructed satellite observations, the real GPS and PL observations were collected first, and the satellite observations were then excluded in the data processing to simulate some scenarios of obstructed sky view. The test area is located on the main campus of the University of Nottingham as shown in Figure 2. The test sites consist of three pseudolite stations (PL1, PL2 and PL3), occupied in turn with one pseudolite, one rover station (Centre) and one reference station (Ddref). 


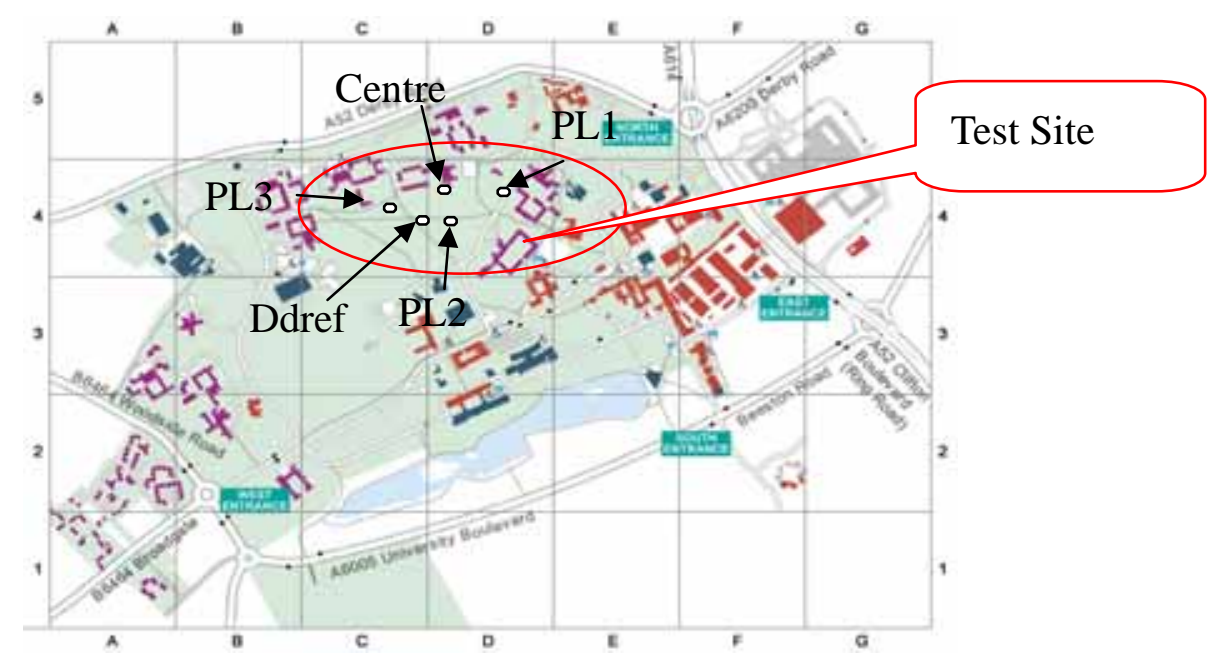

Fig. 2. Test sites of GPS and PL observation

On 2, 5 and 7 August 2003, trials were conducted with two NovAtel DL-4 dual frequency GPS/pseudolite receivers and one IntegriNautics IN200D pseudolite. The pseudolite was set up at PL1 (DOY214), PL2 (DOY217) and PL3 (DOY219) on each respective trial day. At the same time, two receivers were set up one at the unknown station (Centre) and the other at the reference station (Ddref) with known coordinates, both logging GPS and pseudolite measurements. The data sampling rate was $1 \mathrm{~Hz}$. Measurements of two hours duration on each day were collected with this instrumentation.

\section{Simulating Obstructions of the Sky View}

This study is aimed at investigating the effectiveness of a pseudolite placed in an obstructed area. All observed data were simulated according to two scenarios, i.e. two quadrants of sky obstruction and a low elevation angle obstruction. The visible GPS satellites under the obstruction simulations are listed in Table 1, together with the pseudolite transmitter installed at each of the three locations (PL1, PL2 and PL3). Figures 3(a), 3(b) and 3(c) are drawn to depict the sky plots of the obstruction simulations, where the pseudolite was set up at PL2 (DOY217) and coded as PRN32.

Table 1. Visible satellites for different simulation scenarios

\begin{tabular}{c|ccc}
\hline Scenarios of obstruction & $\begin{array}{c}\text { PL1 } \\
\text { (DOY214) }\end{array}$ & $\begin{array}{c}\text { PL2 } \\
\text { (DOY217) }\end{array}$ & $\begin{array}{c}\text { PL3 } \\
\text { (DOY219) }\end{array}$ \\
\hline $\begin{array}{c}\text { Western part of sky } \\
\text { Eastern part of sky }\end{array}$ & $8,10,27,28$ & $8,10,27,28$ & $8,10,27,28$ \\
Low elevation angle of & $10,17,21,26$ & $17,21,26,29$ & $17,21,26,29$ \\
$\operatorname{sky}\left(<40^{\circ}\right)$ & $8,10,17,27$ & $8,10,26,29$ & $10,26,28,29$ \\
\hline
\end{tabular}




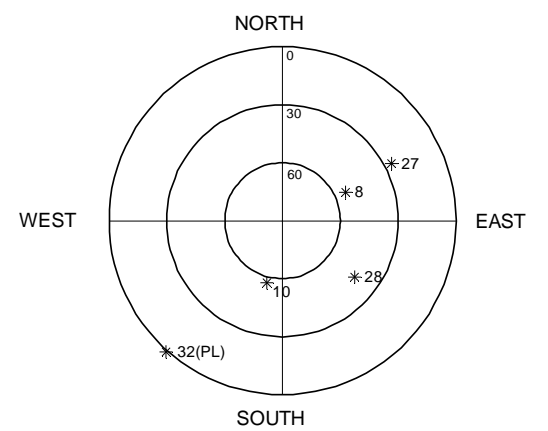

Fig. 3(a). Satellite sky plot of the obstruction in western part of sky (DOY217)

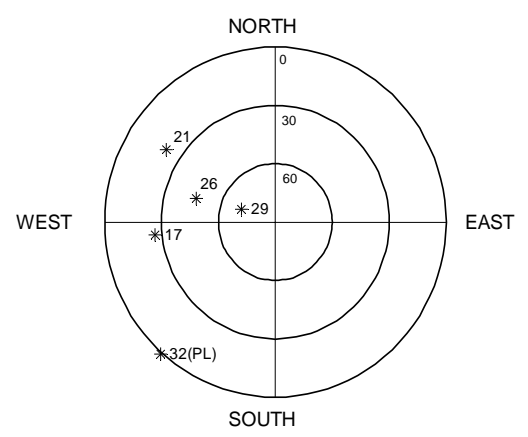

Fig. 3(b). Satellite sky plot of the obstruction in eastern part of sky (DOY217)

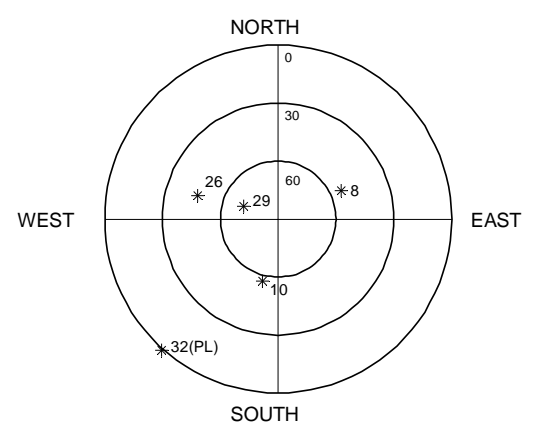

Fig. 3(c). Satellite sky plot of the obstruction at low elevation angle (DOY217)

\section{ANALYSIS OF THE RESULTS}

\section{DOP Values}

The relationship between satellite positioning precision and the geometric distribution has been well investigated for GPS and pseudolite observation [3][7]. Consequently, to evaluate the effectiveness of pseudolite augmented GPS positioning, the simulation studies must consider different obstruction scenarios. The test data sets composed of 600 epochs of the observed data from every trial were input to the in-house developed simulation program. The simulation program computes the DOP values for GPS-only (four satellites) and GPS+PL observations (four satellites with one pseudolite). The mean DOP values for the horizontal coordinates (HDOP) as well as the vertical component (VDOP), after running the program, are listed in Table 2 and Table 3. 
Table 2. Mean HDOP value for the obstruction scenarios

\begin{tabular}{c|ccccc}
\hline $\begin{array}{c}\text { Scenario of } \\
\text { obstruction }\end{array}$ & DOY & GPS-only & GPS+PL & $\begin{array}{c}\text { Impr. } \\
(\%)\end{array}$ & $\begin{array}{c}\text { Mean Impr. } \\
(\%)\end{array}$ \\
\hline \multirow{3}{*}{ Western part of sky } & 214 & 5.8 & 3.6 & 38 & \\
& 217 & 4.1 & 2.2 & 46 & 42 \\
& 219 & 3.8 & 2.2 & 42 & 51 \\
\hline \multirow{3}{*}{ Eastern part of sky } & 214 & 5.4 & 1.6 & 70 & \\
& 217 & 8.7 & 4.3 & 51 & \\
\hline \multirow{3}{*}{ low elevation of sky } & 219 & 7.8 & 5.3 & 32 & 58 \\
$\left(<40^{\circ}\right)$ & 214 & 12.2 & 2.1 & 83 & \\
\hline
\end{tabular}

Table 3. Mean VDOP value for the obstruction scenarios

\begin{tabular}{|c|c|c|c|c|c|}
\hline $\begin{array}{l}\text { Scenario of } \\
\text { obstruction } \\
\end{array}$ & DOY & GPS-only & $\mathrm{GPS}+\mathrm{PL}$ & $\begin{array}{l}\text { Imp. } \\
(\%)\end{array}$ & $\begin{array}{c}\text { Mean Imp. } \\
(\%)\end{array}$ \\
\hline \multirow{3}{*}{ Western part of sky } & 214 & 3.2 & 1.9 & 41 & \multirow{3}{*}{36} \\
\hline & 217 & 4.0 & 1.9 & 53 & \\
\hline & 219 & 3.8 & 3.3 & 13 & \\
\hline \multirow{3}{*}{ Eastern part of sky } & 214 & 9.2 & 2.8 & 70 & \multirow{3}{*}{70} \\
\hline & 217 & 7.9 & 1.5 & 81 & \\
\hline & 219 & 5.7 & 2.4 & 58 & \\
\hline \multirow{3}{*}{$\begin{array}{l}\text { low elevation of sky } \\
\qquad\left(<40^{\circ}\right)\end{array}$} & 214 & 119.8 & 2.2 & 98 & \multirow{3}{*}{83} \\
\hline & 217 & 5.5 & 1.2 & 78 & \\
\hline & 219 & 4.9 & 1.3 & 73 & \\
\hline
\end{tabular}

It can be seen that the HDOP and VDOP values were reduced significantly with the inclusion of the pseudolite observations. The average HDOP reduction ranged from $42 \%$ to $58 \%$ and the corresponding values were $36 \%$ to $83 \%$ for VDOP. The overall reductions in these trials were about 50\% in the HDOP and 63\% in the VDOP. These results indicate that the VDOP is easier to improve than the HDOP when pseudolite observation is added. It is also proved that the pseudolite can provide better improvement for the vertical component than for the horizontal coordinates due to the enhanced signal transmitter geometry by including low elevation pseudolites. 
It is noted that the obstruction simulation was based on using only four satellites in two quadrants (about $180^{\circ}$ ) of the sky view, which is indeed a very poor GPS satellite geometry. When a pseudolite was added into the simulation, the DOP values went down dramatically and the level of the precision is then expected to upgrade. From the obstruction simulation it is evident that a pseudolite can substantially enhance the geometry of the GPS satellite and thereby reduce the DOP values. Moreover, the most significant changes are found for the obstruction simulation of the low elevation angle sky view. This obstruction scenario resulted in a more efficient DOP reduction than in the two quadrant obstructions when adding a pseudolite. The VDOP value improved by $83 \%$, clearly showing the merit of a low elevation pseudolite for improving transmitter geometry and hence the 3D positioning precision.

\section{Positioning Precision}

The positioning results of the rover station were computed using GPS-only and GPS+PL measurements based on L1 double-differenced ambiguity-fixed approach. Table 4 shows the horizontal and vertical positioning results of the GPS-only and the GPS+PL in all abovementioned scenarios of obstruction. The test results reflected in the average standard deviation of the positioning solutions are also shown in Figures 4(a), 4(b) and 4(c) for three trials in all three coordinate components.

Table 4. Positioning precision for the obstruction simulation

\begin{tabular}{|c|c|c|c|c|c|c|c|c|c|c|}
\hline \multirow{2}{*}{\multicolumn{2}{|c|}{ Scenario of }} & \multicolumn{3}{|c|}{ Western part of sky } & \multicolumn{3}{|c|}{ Eastern part of sky } & \multicolumn{3}{|c|}{$\begin{array}{l}\text { Low elevation angle } \\
\text { of sky }\left(<40^{\circ}\right)\end{array}$} \\
\hline & & $\begin{array}{c}\text { GPS-only } \\
(\mathrm{mm}) \\
\end{array}$ & $\begin{array}{c}\text { GPS+PL } \\
(\mathrm{mm}) \\
\end{array}$ & $\begin{array}{l}\text { Impr. } \\
(\%)\end{array}$ & $\begin{array}{c}\text { GPS-only } \\
(\mathrm{mm})\end{array}$ & $\begin{array}{c}\text { GPS+PL } \\
(\mathrm{mm})\end{array}$ & $\begin{array}{l}\text { Impr. } \\
(\%)\end{array}$ & $\begin{array}{c}\text { GPS-only } \\
(\mathrm{mm})\end{array}$ & $\begin{array}{c}\text { GPS+PL } \\
(\mathrm{mm})\end{array}$ & $\begin{array}{l}\text { Impr. } \\
(\%)\end{array}$ \\
\hline DOY & Horizontal & 8.7 & 6.8 & 22 & 22.5 & 10.5 & 53 & 78.3 & 5.9 & 92 \\
\hline 214 & Vertical & 9.4 & 7.6 & 19 & 28.0 & 7.4 & 74 & 99.9 & 4.7 & 95 \\
\hline DOY & Horizontal & 7.1 & 5.9 & 17 & 185.7 & 10.2 & 94 & 5.6 & 4.7 & 16 \\
\hline 217 & Vertical & 9.9 & 3.7 & 63 & 160.5 & 5.7 & 96 & 11.3 & 4.5 & 60 \\
\hline DOY & Horizontal & 8.0 & 5.2 & 35 & 42.8 & 31.6 & 26 & 8.0 & 6.3 & 21 \\
\hline 219 & Vertical & 13.3 & 6.5 & 51 & 39.9 & 29.1 & 27 & 8.3 & 6.8 & 18 \\
\hline
\end{tabular}

It can be generally seen from Figures 4(a), 4(b) and 4(c) that the test results based on using GPS+PL measurements clearly improved in all coordinate components. However, different levels of change in positioning precision are also found in Table 4. It is noted that a significant level of reduction in the error in horizontal component was 
from $186 \mathrm{~mm}$ (GPS-only) to $10 \mathrm{~mm}$ (GPS+PL), whereas a minor reduction from $7 \mathrm{~mm}$ (GPS-only) to $6 \mathrm{~mm}$ (GPS+PL) was also observed on DOY217 for different scenarios of obstruction. It is also found that when pseudolite measurements were added, the vertical precision significantly improved from $161 \mathrm{~mm}$ to $6 \mathrm{~mm}$ or slightly improved from $8 \mathrm{~mm}$ to $7 \mathrm{~mm}$ on DOY217 and DOY 219, respectively, based on different obstruction scenarios of simulations. It therefore concludes that the positioning precision can be enhanced by adding pseudolite measurements, but the improvement level is dependent on the setting-up place of the pseudolite and the obstructed conditions of the satellite sky view.

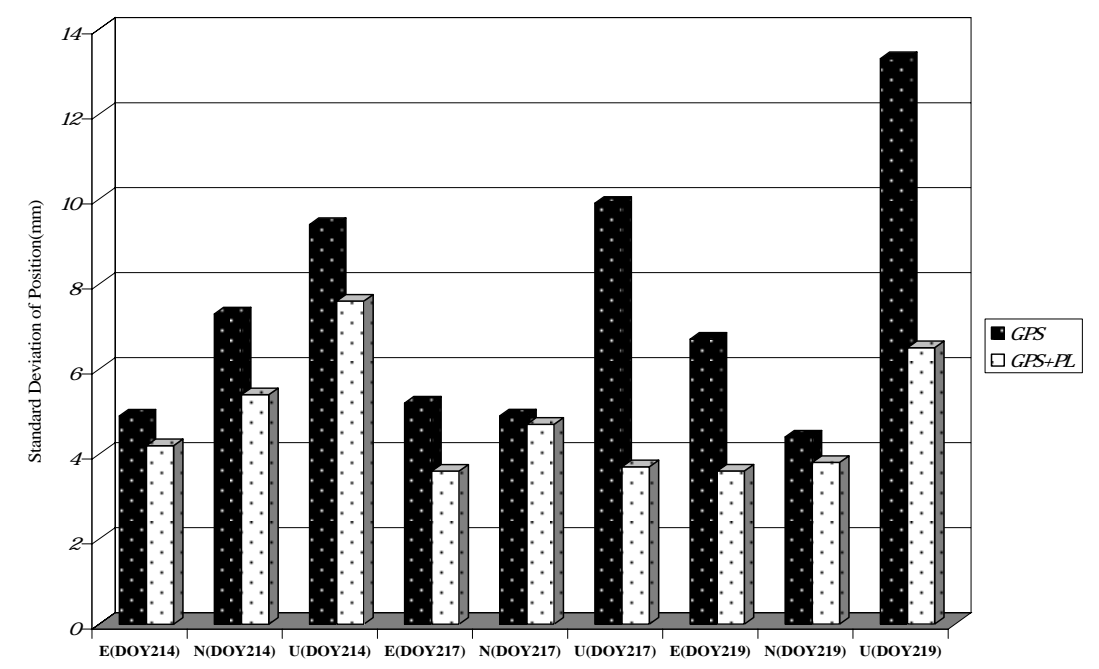

Fig. 4(a). Coordinate precision for the western part of sky obstructed

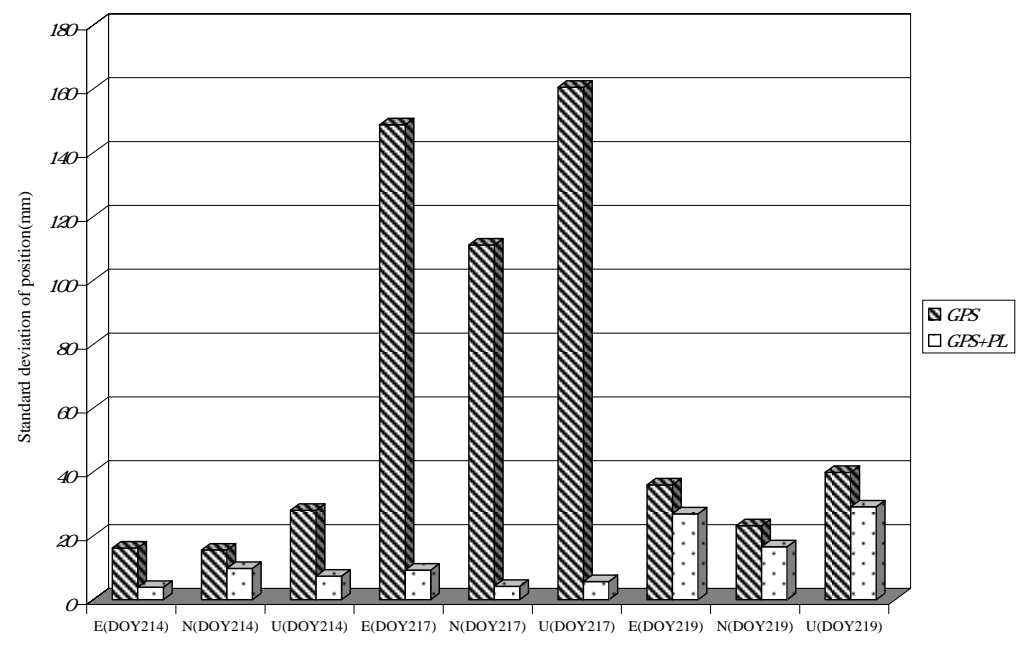

Fig. 4(b). Coordinate precision for the eastern part of the sky obstructed 


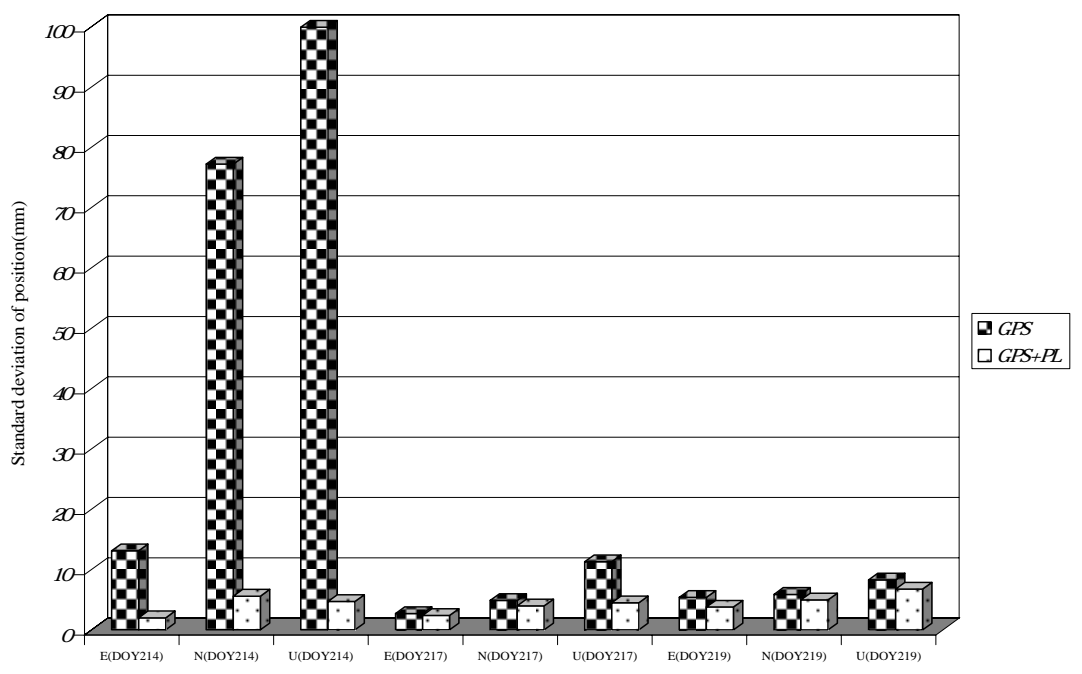

Fig. 4(c). Coordinate precision for the low elevation angle sky obstructed

It is worth noting that when the low elevation angle view of the sky was blocked and the pseudolite measurements were added in, the horizontal precision was improved from $30 \mathrm{~mm}$ to $5 \mathrm{~mm}$, and the vertical component improved from $40 \mathrm{~mm}$ to $5 \mathrm{~mm}$, for an average of the three trials. Overall, the 3D positioning precision can be maintained to an average level of $8 \mathrm{~mm}$ when using the pseudolite to assist the GPS in the obstructed areas.

It is generally believed that the precision of the vertical component can be improved more than the horizontal one when the pseudolite measurements are added. In this study, the GPS positioning in an obstructed area with only one pseudolite could improve the average precision by $56 \%$ in height, $46 \%$ in the eastern component and $37 \%$ in northern component, or $42 \%$ in the horizontal coordinates (see Table 5). Hence, pseudolite aided GPS positioning is seen to greatly enhance the GPS positioning precision in the obstructed areas.

Table 5. Average improvement ratio based on GPS $+P L$ measurements

\begin{tabular}{c|cccc}
\hline Scenario of obstruction & East(\%) & North(\%) & Horizontal(\%) & Height(\%) \\
\hline Western part of sky & 30 & 15 & 25 & 44 \\
Eastern part of sky & 65 & 54 & 58 & 66 \\
Low elevation of sky $\left(<40^{\circ}\right)$ & 42 & 42 & 43 & 58 \\
Average & 46 & 37 & 42 & 56 \\
\hline
\end{tabular}

To depict the positioning results of the epoch solution, Figure 5(a) to Figure 5(f) are shown for the pseudolite located at PL2 (DOY217) and the blocked eastern sky view. It can be seen that the GPS-only positioning results for the three coordinate 
components of the static station were all over $100 \mathrm{~mm}$. When the GPS pseudolite measurements were added in, the positioning time series of three components effectively reduced to a level of less than $10 \mathrm{~mm}$.

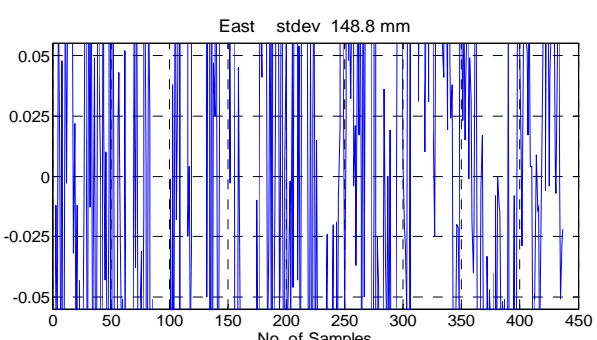

Fig. 5(a). E-component coordinates precision (GPS-only) in the eastern part of the sky blocked (DOY217)

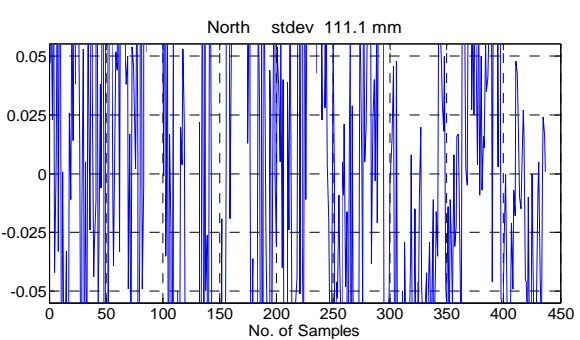

Fig. 5(c). N-component coordinates precision (GPS-only) in the eastern part of the sky locked (DOY217)

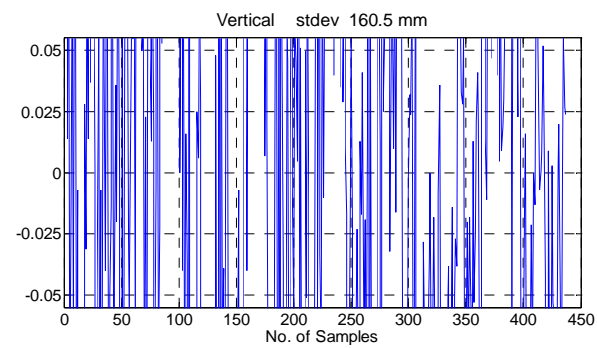

Fig. 5(e). U-component coordinates precision (GPS only) in the eastern part of the sky blocked (DOY217)

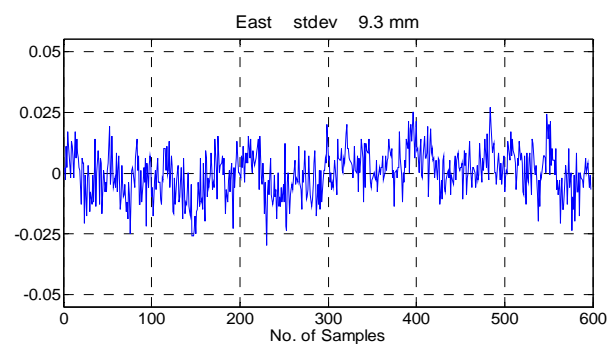

Fig. 5(b). E-component coordinates precision (GPS +PL) in the eastern part of the sky blocked (DOY217)

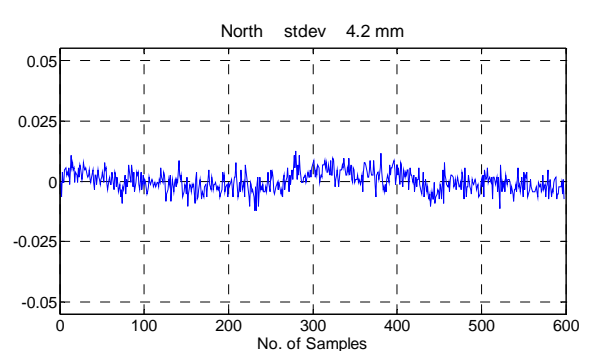

Fig. 5(d). N-component coordinates precision (GPS +PL) in the eastern part of the sky blocked (DOY217)

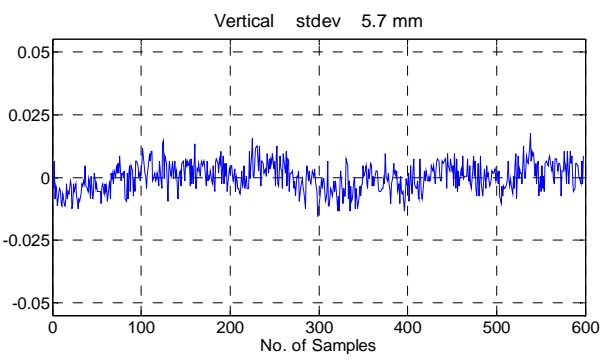

Fig. 5(f). U-component coordinates precision (GPS +PL) in the eastern part of the sky blocked (DOY217)

\section{CONCLUDING REMARKS}

When GPS positioning is carried on in the obstructed areas, it creates a poor quality of satellite geometry. This study has investigated the effectiveness and improvement of pseudolite augmented GPS positioning under the obstructed conditions. It has been found that the DOP value can be reduced by more than $35 \%$ with an improvement in the positioning precision of around 55\% and $40 \%$ for the vertical and horizontal component, respectively. It is evident that GPS positioning 
can be substantially augmented by adding pseudolite measurements. The research has also revealed that sub-centimetric 3D positioning precision in the obstructed areas could be achieved with the help of the pseudolite measurements. From this study it is shown that with the inclusion of a low elevation angle pseudolite in the data processing, the quality of the vertical coordinate could be effectively improved by more than $50 \%$. In other words, the overall precision of the GPS positioning results could be improved with the addition of the measurements from a low elevation angle pseudolite, by reducing the obstructed effect of the satellite sky view.

\section{References}

1. Grejner-Brzezinska, D. and Yi, Y., 2003. Experimental GPS/INS/Pseudolite System for Kinematic Positioning. Survey Review, 37(288): 113-126.

2. Hofmann-Wellenhof, B., Lichtenegger, H. and Collins, J., 2001. Global Positioning System Theory and Practice. $5^{\text {th }}$ Edition. Springer-Verlag.

3. Meng, X., Roberts, G. W., Dodson, A. H., Cosser, E., Barnes, J. and Rizos, C., 2004. Impact of GPS satellite and pseudolite geometry on structural deformation monitoring: analytical and empirical studies. Journal of Geodesy, 77: 809-822.

4. Ning, F. S., Kao, S. P., Chang, C. C. and Meng, X., 2004. Preliminary test of using pseudolite to improve GPS precision. Proceedings of First FIG International Symposium on Engineering Surveys for Construction Works and Structural Engineering, Nottingham, UK.

5. Parkinson, B. W. and Fitzgibbon, K. T., 1986. Optimal locations of pseudolite for differential GPS. Navigation, 33(4): 259-283.

6. Parkinson, B. W., 1996. GPS error analysis. in Global Positioning System: Theory and Applications. edited by B. W. Parkinson, J. J. Spilker, P. Axelard and P. Enge. American Institute of Aeronautics and Astronautics, 469-483.

7. Santerre R., 1991. Impact of GPS satellite sky distribution. Manuscr Geod, 16: 28-35.

8. Wang, J., Dai, L., Tsujii, T., Rizos, C., Grejner-Brzezinska, D. and Toth, C. K., 2001. GPS/INS/Pseudolite integration: concepts, simulation and testing. Proceedings of the U.S. Institute of Navigation (GPS-2001), 2708-2715.

9. Wang, J., Tsujii, T., Rizos, C., Dai, L. and Moore, M., 2001. GPS and pseudo-satellites integration for precise positioning. Geomatics Research Australasia, 74: 103-117. 